\title{
A Regional Modeling Study of Climate Change Impacts on Warm-Season Precipitation in the Central United States*
}

\author{
MELISSA S. BUKOVSKY \\ National Center for Atmospheric Research, Boulder, Colorado \\ DAVID J. KAROLY \\ School of Earth Sciences, University of Melbourne, Melbourne, Victoria, Australia
}

(Manuscript received 24 September 2009, in final form 2 November 2010)

\begin{abstract}
In this study, the Weather Research and Forecasting (WRF) model is employed as a nested regional climate model to dynamically downscale output from the National Center for Atmospheric Research's (NCAR's) Community Climate System Model (CCSM) version 3 and the National Centers for Environmental Prediction (NCEP)-NCAR global reanalysis (NNRP). The latter is used for verification of late-twentieth-century climate simulations from the WRF.

This analysis finds that the WRF is able to produce precipitation that is more realistic than that from its driving systems (the CCSM and NNRP). It also diagnoses potential issues with and differences between all of the simulations completed. Specifically, the magnitude of heavy 6-h average precipitation events, the frequency distribution, and the diurnal cycle of precipitation over the central United States are greatly improved. Projections from the WRF for late-twenty-first-century precipitation show decreases in average May-August (MJJA) precipitation, but increases in the intensity of both heavy precipitation events and rain in general when it does fall. A decrease in the number of 6-h periods with rainfall accounts for the overall decrease in average precipitation. The WRF also shows an increase in the frequency of very heavy to extreme 6-h average events, but a decrease in the frequency of all events lighter than those over the central United States. Overall, projections from this study suggest an increase in the frequency of both floods and droughts during the warm season in the central United States.
\end{abstract}

\section{Introduction}

Many of the potential consequences of climate change on water-related issues are based on predicted changes in the characteristics of precipitation; yet, on a global scale, precipitation prediction is still lacking, despite simulated trends that generally match observed trends in precipitation (Dai 2006). Warm-season deep convection is the main cause of precipitation in many parts of the United States, yet climate model simulations of warm-season,

\footnotetext{
* Supplemental information related to this paper is available at the Journals Online Web site: http://dx.doi.org/10.1175/ 2010JCLI3447.s1.

Corresponding author address: Melissa S. Bukovsky, National Center for Atmospheric Research, P.O. Box 3000, Boulder, CO 80307-3000.

E-mail: bukovsky@ucar.edu
}

continental convection and associated precipitation do not compare well with observations. Errors in the distribution, frequency, intensity, and diurnal cycle of simulated precipitation are common.

Much of the uncertainty involved in predictions of precipitation under climate change scenarios is rooted in model resolution and dependence on convective parameterization (Duffy et al. 2003; Leung et al. 2003; Liang et al. 2004b; Sun et al. 2006). Uncertainty compounds in the simulation of precipitation at regional scales owing to resolution issues; coarse-resolution climate models have problems with topography, eddy processes, and subgrid parameterizations, giving them little predictive ability at regional scales (Duffy et al. 2003). This creates additional error that will propagate through to the projection of precipitation. Unfortunately, higher-resolution models have problems reproducing regional-scale precipitation features as well, again due to their dependence on convective parameterization (Liang et al. 2006). Commonly 
noted problems include a failure to represent the nocturnal maximum in convection that exists over the U.S. Great Plains, precipitation that is too early, too frequent, and too light; and an unrealistic diurnal cycle (Randall et al. 1991; Garratt et al. 1993; Dai 1999; Lin et al. 2000; Groisman et al. 2000; Zhang et al. 2003; Davis et al. 2003; Liang et al. 2004b).

In the central United States, convective schemes have problems with the main mode of convection, but at coarse resolutions, the necessary mesoscale processes that produce favorable conditions for mesoscale convective systems (MCSs) may not be captured as well. That is, processes that converge moisture into the central United States produce a low-level jet and, then, convert that converged moisture into precipitation near the northern terminus of the low-level jet (LLJ) must be simulated (Augustine and Caracena 1994).

Nested regional modeling allows for higher-resolution orography, land-sea contrasts, land surface characteristics, and for the regional model to develop local and mesoscale flows (depending on its resolution) that can then interact with the large-scale circulation induced by the initial and boundary condition sources. It also allows regional climate features and extreme events to be more realistically simulated and has been shown to produce results that are more accurate than those from the driving GCM or reanalysis (Takle et al. 1999; Pan et al. 2001; Liang et al. 2001; Anderson et al. 2003; Leung et al. 2003; Liang et al. 2004a; Fowler et al. 2005; Frei et al. 2006; Liang et al. 2006; Salathé et al. 2008; Leung and Qian 2009).

This study aims to circumvent some of the issues involved in simulating warm-season precipitation in the United States in global climate models by using the Weather Research and Forecasting (WRF) model as a nested regional climate model (RCM). Because the use of the WRF for dynamic downscaling is not as well documented as the use of other regional models, there is much that still needs to be explored with regard to its ability to simulate regional climate. Thus, its ability to realistically simulate warm-season precipitation over the United States is presented in section 3 . As with the other sections, section 3 will focus on the central United States, where the simulation of warm-season precipitation is particularly challenging, as discussed above.

Projections from the WRF are given in section 4. The last parts of sections 3 and 4 contain a more in-depth explanation of the simulations presented. The latter is included because a more detailed projection does not automatically justify increased confidence in that simulation. Examining some of the underlying processes responsible for the projected changes and differences between the model simulations in the present helps quantify part of the uncertainty involved in climate simulation and projection. The final section provides a summary and final discussion of the results presented.

\section{Methods}

Version 3.0.1 of the Advanced Research version of the WRF (ARW) was used in this study. Simulations were produced with a $30-\mathrm{km}$ horizontal-resolution domain nested inside of a larger $90-\mathrm{km}$ horizontal-resolution domain with 28 vertical levels. For all simulations, the WRF was initialized on 23 April of each simulated year and run through 31 August. Feedback between the nest and its parent domain is off (i.e., one-way nesting is used). There are many options available in the WRF, and numerous combinations were tested to find an optimal setup for this particular study. Part of this process is documented in Bukovsky and Karoly (2009), as varying WRF options had, in some cases, large and unexpected impacts on the simulations. The physical parameterizations chosen for use in this case are the following:

- a Kain-Fritsch convective parameterization scheme (KF CPS; Kain and Fritsch 1992; Kain 2004),

- WRF single-moment five-class microphysics (Hong et al. 2004),

- the Community Atmosphere Model 3.0 (CAM) longand shortwave radiation package (Kiehl et al. 1998, Collins 2001, Collins et al. 2002),

- the Monin-Obukhov surface layer scheme (Skamarock et al. 2005),

- the Noah land surface model (Ek et al. 2003), and

- the Yonsei University (YSU) planetary boundary layer scheme (Hong et al. 2006).

Initial and boundary conditions were derived from two sources. To start, the first version of the NCEP-NCAR global reanalysis project (NNRP; Kalnay et al.1996) was used in order to facilitate a direct comparison with reality from 1990 to 1999. The NNRP has a horizontal resolution of $2.5^{\circ}$ with 17 pressure levels (excluding the surface) and is available in 6-h increments. This combination of the WRF and NNRP is hereafter referred to as the WRF-NNRP.

Initial and boundary conditions were also derived from CCSM 3.0 runs b030.030e and b030.042e, from 1990 to 1999 and 2090 to 2099, respectively, produced in support of the Intergovernmental Panel on Climate Change's (IPCC) Fourth Assessment Report (AR4), the combination of which is referred to hereafter as WRF-CCSM. Simulation b030.030e used the Special Report on Emissions Scenario (SRES; Nakicenovic et al. 2000) climate of the twentieth-century $(20 \mathrm{C} 3 \mathrm{M})$ emissions scenario, while b030.042e used the high-level A2 emissions scenario. For reference, a time series of average 2-m temperature for 


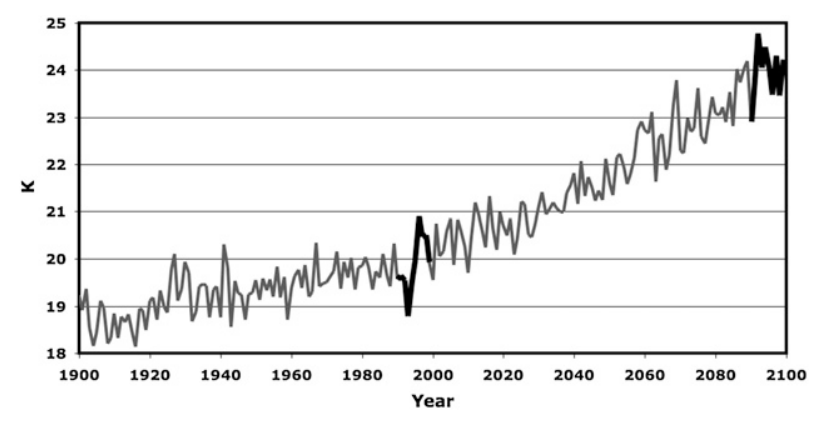

FIG. 1. MJJA average 2-m temperature from the CCSM for the region shown in Fig. 2d from 1900 to 1999 using the 20C3M emission scenario and from 2000 to 2099 from the A2 emission scenario. The two decades utilized in this study are emphasized in black.

May-August from the CCSM 3.0 over the 90-km WRF domain region is shown in Fig. 1. The CCSM 3.0 has a triangular spectral truncation at T85 (approximately $1.4^{\circ}$ ) and 26 sigma-hybrid vertical layers (Collins et al. 2006).

\section{Significance testing}

Some of the differences presented in this paper are tested for statistical significance. Due to the limited number of years simulated in each century and the unknown distribution of some of the variables to be tested, bootstrapping with bias correction and acceleration was used to estimate confidence intervals following von Storch and Zwiers (1999) and Efron and Tibshirani (1993). In every application of this method, the same number of seasons from the present and the future were pooled as if drawn from the same distribution [10 May-August (MJJA) seasons from both the 1990s and the 2090s]. From this pool, two lots of $x$ number of cases were randomly selected (where $x$ is the number of seasons used from a given decade in the pooling), with replacement, and the difference between the two randomly sampled lots was estimated. Monte Carlo simulation was used to generate 1000 bootstrap samples of each difference between the present and the future in this manner, giving a distribution from which the lower- and upper-tail critical values were estimated ( 0.05 and 0.95 , respectively) and then corrected.

\section{Evaluation of present climate}

\section{a. Average precipitation}

Figure 2 shows average MJJA precipitation from the North American Regional Reanalysis (NARR), NNRP, CCSM, WRF-NNRP, and WRF-CCSM. The NARR data used in Fig. 2a have a horizontal resolution of $32 \mathrm{~km}$ (close to the resolution of the inner WRF nest), and the average warm-season precipitation in the NARR and its diurnal cycle over the continental United States are superior to those found in other widely used reanalyses and are comparable to those in the Climate Prediction Center's hourly, observationally based precipitation dataset, and other observation-based precipitation estimates (Bukovsky and Karoly 2007; Higgins et al. 1996; Ruane 2010). It does have some problems over oceans, islands, and at country boundaries, but is conveniently gridded and is available for the 1990-99 period used in this study, facilitating an easy comparison with the simulations.

The average precipitation from the WRF-NNRP in Figs. 2c and 2d is not perfect, but as shown in Bukovsky and Karoly (2009), it agrees better with the NARR than does the NNRP precipitation, the source of the initial and boundary conditions for this simulation. There is a slight low bias toward average precipitation in the southcentral United States, and a high bias in the northeast, but it does capture both the maximum in the southeast and also the Great Plains. In contrast to the plethora of precipitation over the Southeast in the NNRP (Fig. 2b) and the lack of the secondary plains maximum, the WRFNNRP simulated precipitation is a definite improvement.

Given the differences in the initial and boundary conditions, the average precipitation from the WRF-CCSM in Figs. $2 \mathrm{f}$ and $2 \mathrm{~g}$ for the 1990s was not expected to exactly match that from the WRF-NNRP, but as shown, it does exhibit some of the same basic characteristics that mark average warm-season precipitation in the United States. There is a dry bias in the WRF-CCSM compared to the WRF-NNRP, especially throughout the central part of the United States, but it does produce a relative maximum in the Great Plains/Midwest region, unlike the CCSM (Figs. 2e-g). As illustrated in Fig. 2e, the CCSM does not produce this maximum and, instead, produces too much precipitation in the southern and high plains that is possibly orographic in nature.

A few simple comparison metrics for the differences in average precipitation in Fig. 2 are described in Table 1 for the 90-km domain over U.S. land only, and the 30-km domain for the central U.S. region (defined by the box in Fig. 2d). To facilitate this comparison, all values were interpolated onto an intermediate, matching, $1^{\circ} \times 1^{\circ}$ latitude-longitude grid. Overall, these metrics confirm the improvement in the magnitude of the average precipitation in the WRF-NNRP versus the NNRP and the dry bias in the WRF-CCSM. The Pearson correlation of the spatial pattern (which is insensitive to the bias) indicates that the WRF-CCSM does provide a significantly better pattern of precipitation over the central United States than does the CCSM 3.0, and both WRF simulations correlate better with the NARR than with their driver in this region. The lower value of this correlation between the NARR and the WRF-NNRP, versus the 

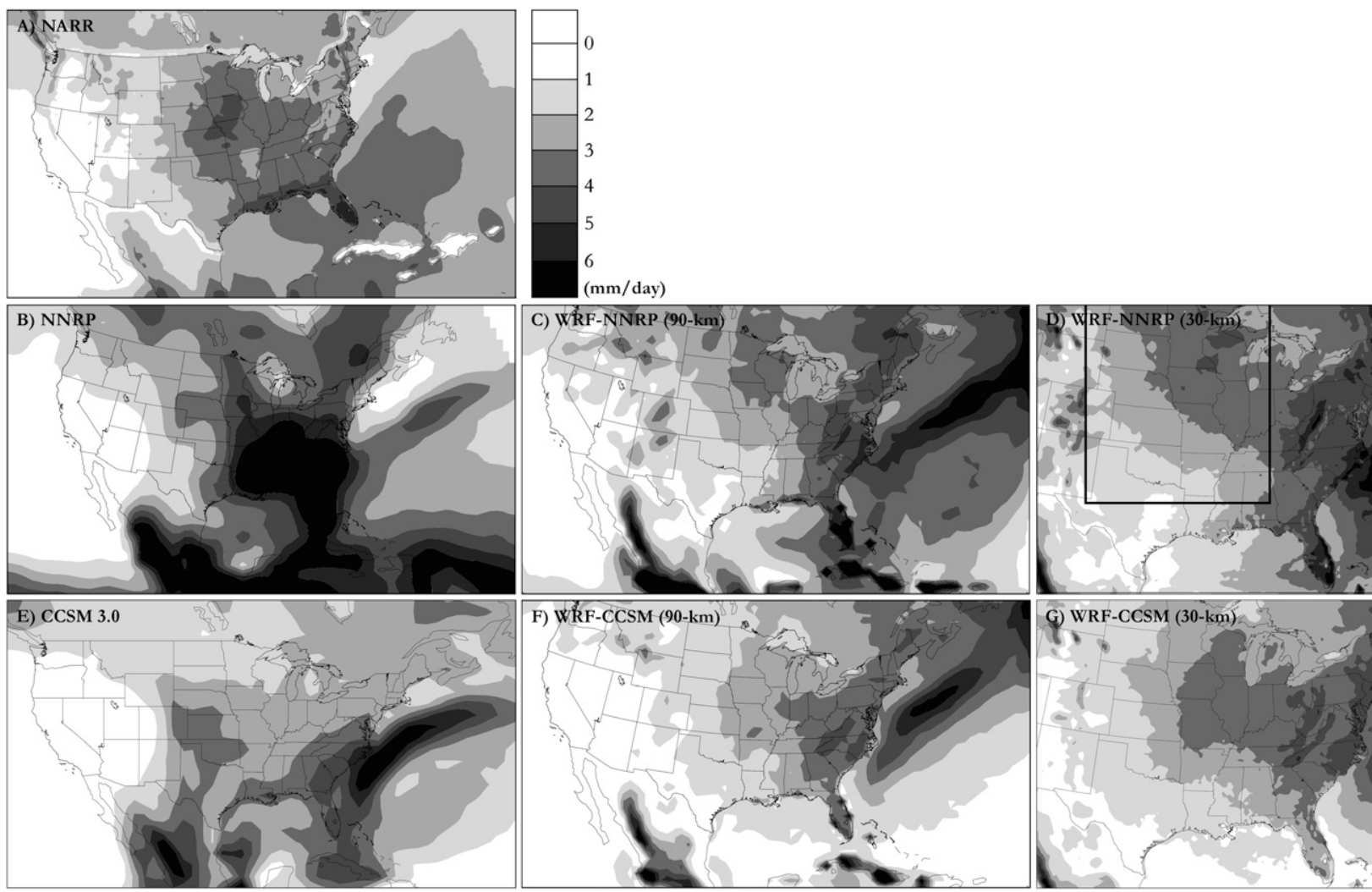

FIG. 2. MJJA average precipitation ( $\mathrm{mm} \mathrm{day}^{-1}$ ) for 1990-99 from (a) NARR, (b) NNRP, (c) WRF-NNRP (90-km parent domain), (d) WRF-NNRP (30-km nest), (e) CCSM, (f) WRF-CCSM (90-km parent domain), and (g) WRF-CCSM (30-km nest).

NARR and the NNRP, are likely due to the northward displacement of the Great Plains maximum in the WRFNNRP, which would reverse the precipitation gradient in the northern half of the central U.S. region and decrease its pattern correlation. Values of RMSEs in Table 1 are clearly lower between both WRF simulations and the NARR, than between the NARR and the drivers in the central United States.

\section{b. Precipitation diurnal cycle and extremes}

Many reanalyses, climate models, and mesoscale forecast models have difficulties capturing the diurnal cycle of precipitation, especially in the Great Plains during the warm season (e.g., Davis et al. 2003; Bechtold et al. 2004; Bukovsky and Karoly 2007). As illustrated in Fig. 3, both 30-km WRF simulations capture the timing and the longitudinally bounded corridor of warm-season precipitation in the central United States in a much more realistic manner than either the NNRP or the CCSM. The precipitation in the 90-km WRF simulations suffers from problems similar to those in the NNRP and the CCSM: there is no eastward propagation from late afternoon through evening shown at the coarser resolution. Even with a $30-\mathrm{km}$ horizontal resolution, it is not expected that this occurs for the "right" reason. ${ }^{1}$ However, it does indicate that heavier precipitation events are occurring and not only at the time of maximum solar heating for the day; thus, there must be other mechanisms in play that the WRF and its CPS are picking up on to produce precipitation in the late afternoon, evening, and overnight in the Great Plains. ${ }^{2}$

One of the greatest benefits to using the WRF as an $\mathrm{RCM}$, in terms of the simulated precipitation, emerges in the frequency distribution of precipitation rates. As mentioned in the introduction, climate models generally produce too much light precipitation and too little heavy precipitation. As shown in Fig. 4, dynamically downscaling the CCSM greatly improves the distribution of

\footnotetext{
${ }^{1}$ Convective systems would not be realistically structured MCSs at either 30 - or $90-\mathrm{km}$ resolution, after all. In this case, they more closely resemble the convective "blobs" of forecasting models that were previously run near this resolution.

${ }^{2}$ To complement this discussion, MJJA precipitation animations from 1991 WRF-NNRP and WRF-CCSM 30-km simulations have been included as supplemental online material at the Journals Online Web site (http://dx.doi.org/10.1175/2010JCLI3447.s1). The features and differences presented in the text are apparent in the animations of this one arbitrarily chosen season.
} 
TABLE 1. Comparisons between the NARR, the WRF simulations, and their drivers using area averages, pattern correlations, and RMSEs. To facilitate this comparison, all sets of data were interpolated to an intermediate $1^{\circ} \times 1^{\circ}$ latitude-longitude grid.

\begin{tabular}{|c|c|c|c|c|c|c|}
\hline & Set 1 & Set 2 & $\begin{array}{c}\text { Region } \\
\text { (WRF domain) }\end{array}$ & $\begin{array}{c}\text { Area average } \\
\text { difference } \\
(\text { Set } 1-\text { Set } 2)\end{array}$ & $\begin{array}{c}\text { Pattern } \\
\text { corr }\end{array}$ & RMSE \\
\hline \multirow[t]{12}{*}{ 2-m temp $(\mathrm{K})$} & NARR & NNRP & \multirow[t]{6}{*}{ U.S. land $(90 \mathrm{~km})$} & 1.14 & 0.92 & 2.14 \\
\hline & NARR & WRF-NNRP & & -1.39 & 0.92 & 2.43 \\
\hline & NNRP & WRF-NNRP & & -2.53 & 0.95 & 3.04 \\
\hline & NARR & CCSM & & -0.25 & 0.88 & 2.25 \\
\hline & NARR & WRF-CCSM & & -1.67 & 0.90 & 2.74 \\
\hline & CCSM & WRF-CCSM & & -1.42 & 0.95 & 2.16 \\
\hline & NARR & NNRP & \multirow[t]{6}{*}{ CUS (30 km) } & 1.07 & 0.96 & 1.38 \\
\hline & NARR & WRF-NNRP & & -2.54 & 0.96 & 2.94 \\
\hline & NNRP & WRF-NNRP & & -3.61 & 0.96 & 3.90 \\
\hline & NARR & CCSM & & -0.74 & 0.89 & 1.89 \\
\hline & NARR & WRF-CCSM & & -2.63 & 0.94 & 3.11 \\
\hline & CCSM & WRF-CCSM & & -1.88 & 0.92 & 2.63 \\
\hline \multirow[t]{12}{*}{ Precipitation rate $\left(\mathrm{mm} \mathrm{day}^{-1}\right)$} & NARR & NNRP & \multirow[t]{6}{*}{ U.S. land $(90 \mathrm{~km})$} & -1.06 & 0.82 & 1.85 \\
\hline & NARR & WRF-NNRP & & -0.48 & 0.54 & 1.04 \\
\hline & NNRP & WRF-NNRP & & 0.58 & 0.53 & 2.27 \\
\hline & NARR & CCSM & & 0.27 & 0.77 & 0.81 \\
\hline & NARR & WRF-CCSM & & 0.46 & 0.74 & 0.94 \\
\hline & CCSM & WRF-CCSM & & 0.19 & 0.70 & 0.86 \\
\hline & NARR & NNRP & \multirow[t]{6}{*}{ CUS (30 km) } & -1.16 & 0.62 & 1.91 \\
\hline & NARR & WRF-NNRP & & 0.27 & 0.45 & 0.86 \\
\hline & NNRP & WRF-NNRP & & 1.43 & 0.28 & 2.31 \\
\hline & NARR & CCSM & & 0.54 & 0.26 & 0.98 \\
\hline & NARR & WRF-CCSM & & 0.58 & 0.69 & 0.83 \\
\hline & CCSM & WRF-CCSM & & 0.04 & -0.02 & 0.96 \\
\hline \multirow[t]{6}{*}{ 850-hPa specific humidity $\left(\mathrm{g} \mathrm{kg}^{-1}\right)$} & NARR & NNRP & \multirow[t]{6}{*}{ CUS (30 km) } & 0.13 & 0.93 & 0.46 \\
\hline & NARR & WRF-NNRP & & 0.91 & 0.69 & 1.28 \\
\hline & NNRP & WRF-NNRP & & 0.78 & 0.57 & 1.24 \\
\hline & NARR & CCSM & & 2.74 & 0.77 & 2.85 \\
\hline & NARR & WRF-CCSM & & 2.00 & 0.83 & 2.12 \\
\hline & CCSM & WRF-CCSM & & -0.74 & 0.65 & 1.08 \\
\hline \multirow[t]{6}{*}{ 850-hPa north-south wind component $\left(\mathrm{m} \mathrm{s}^{-1}\right)$} & NARR & NNRP & \multirow[t]{6}{*}{ CUSLLJ (30 km) } & -0.07 & 0.97 & 0.48 \\
\hline & NARR & WRF-NNRP & & 0.48 & 0.92 & 1.19 \\
\hline & NNRP & WRF-NNRP & & 0.56 & 0.94 & 1.11 \\
\hline & NARR & CCSM & & -0.07 & 0.89 & 1.08 \\
\hline & NARR & WRF-CCSM & & -1.33 & 0.90 & 2.12 \\
\hline & CCSM & WRF-CCSM & & -0.93 & 0.96 & 1.42 \\
\hline
\end{tabular}

CUS $=$ central United States, a region shown in Fig. 2d.

precipitation. There is now a more realistic tail of heavy precipitation rates and fewer light precipitation events [at both $30 \mathrm{~km}$ (Fig. 4c) and $90 \mathrm{~km}$ (not shown)]. Furthermore, the majority of the precipitation is produced by the convective parameterization and is not large scale in nature (Fig. 4d). The WRF-CCSM for this region may contain more extreme precipitation rates than the NARR, but the NARR may not contain a good representation of these extreme events either since they may also be constrained by the modeling system used to produce the NARR and, specifically, its CPS. Unfortunately, there is no better way to verify this distribution.

Similarly, the simulations from the WRF-CCSM also improve the magnitude of heavy precipitation rates as well as the proportion of precipitation they are responsible for in the central United States, as illustrated in Fig. 5 for 99th percentile events. This can also be said for other extreme percentile values. Given that the values calculated in Fig. 5 


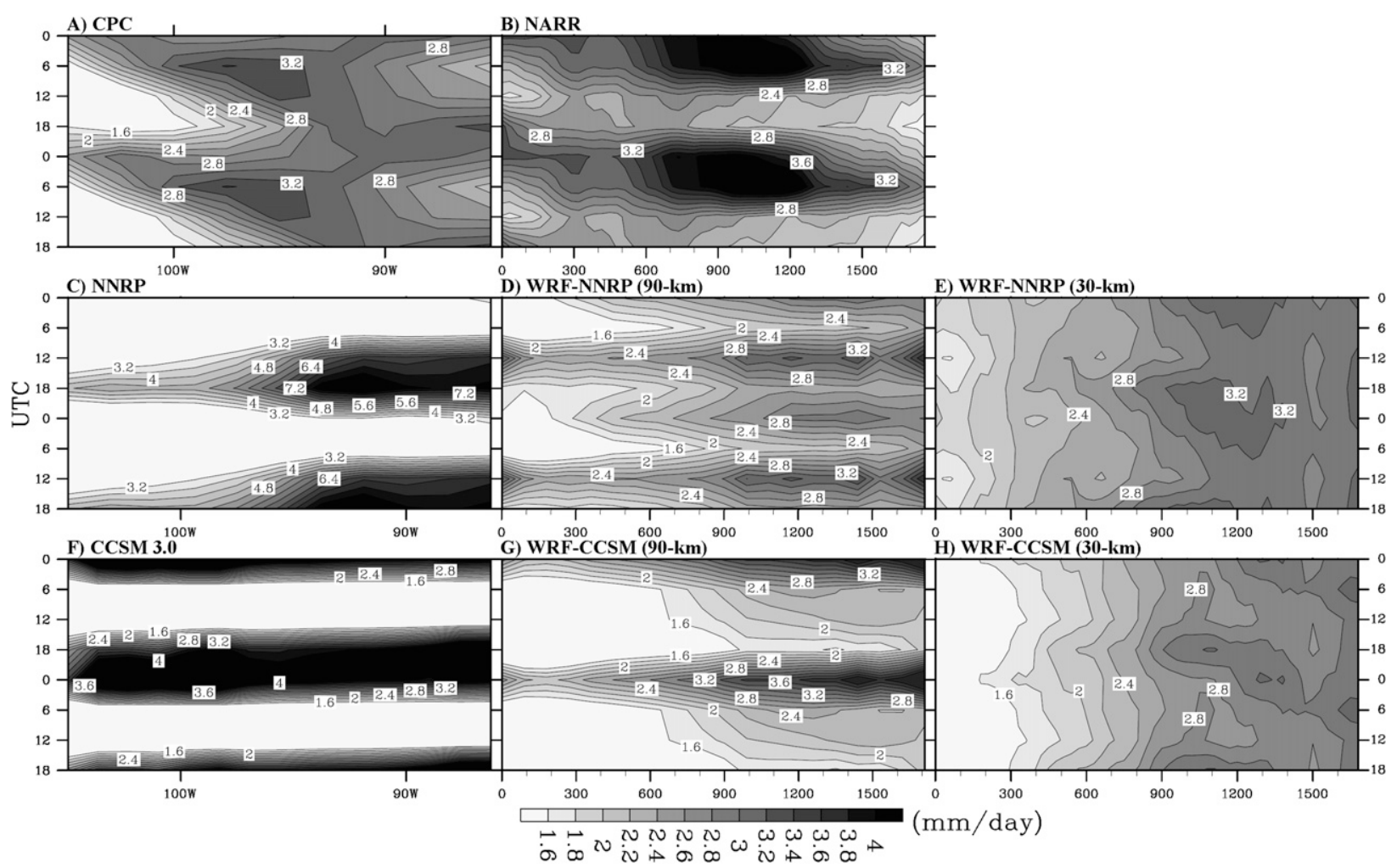

FIG. 3. Hovmöller diagrams of the 1990-99 MJJA average of the precipitation rate for the central United States (the region outlined in Fig. 2d), for the 6-hourly times shown. The contour interval and values used in (c) (the NNRP) are twice those in the other panels; they range from 3.2 to 8.0 by $0.4 \mathrm{~mm} \mathrm{day}^{-1}$ instead of 1.6 to 4.0 by $0.2 \mathrm{~mm} \mathrm{day}^{-1}$. The time axis has been repeated twice for ease of comparison given the nocturnal nature of the precipitation in this region. Note that because of the different map projections and original grid structure of the data, the regions over which the averages are completed may vary slightly, and the $x$ axes in the center and right column panels are in kilometers instead of degrees of longitude. The Climate Prediction Center (CPC) gauge-based analysis, though at a coarse $2.5^{\circ}$ resolution, has been included in this comparison because the corridor of nocturnal precipitation in the NARR is too broad compared to other observations.

used only precipitation rates above a trace, the 99th percentile is equivalent to a return period of approximately one 6-hourly event at the rate shown per year per grid point. As expected, the 99th percentile values of precipitation in the CCSM are approximately half those from the NARR and the WRF-CCSM (note the difference in scale between Figs. 5d and 5a-c). However, the axis of greatest magnitude between the NARR and the WRF-CCSM is different, and is suggestive of cold-frontal forcing for most of the events that produce these values in the WRFCCSM. A similar improvement over the CCSM is also seen in the proportion of precipitation from heavy events, even though this particular metric would not necessarily be subject to the same bias.

\section{c. Near-surface temperature}

Using the WRF as an RCM allows for much more detail in the spatial distribution of near-surface temperature. This, of course, improves regions of cooler average temperature at higher elevations. Despite this, the WRF does inherit and modify bias from its drivers, and this is apparent in near-surface temperature. This is illustrated in Fig. 6 and through Table 1 for 2-m temperature. The bias added by the WRF is particularly visible in the Great Plains, where temperatures run up to about $5^{\circ}$ warmer than the driving system in the southern plains (with the greatest bias over Oklahoma or the Texas Panhandle, depending on which driver is considered). Over the central United States, the WRF-NNRP is about $3.6^{\circ}$ warmer than the NNRP and the WRF-CCSM is about $1.9^{\circ}$ warmer than the CCSM 3.0 on average (see Table 1 ). This warm bias could be rooted in the model setup or any number of feedbacks. For instance, the dry bias in the plains, particularly the southern plains, could be contributing to the temperature bias via a positive radiative feedback from insufficient cloud cover related to the insubstantial precipitation in this region. Further diagnostics related to the differences between the WRF simulations and observations are discussed in the next subsection, starting again with precipitation. 


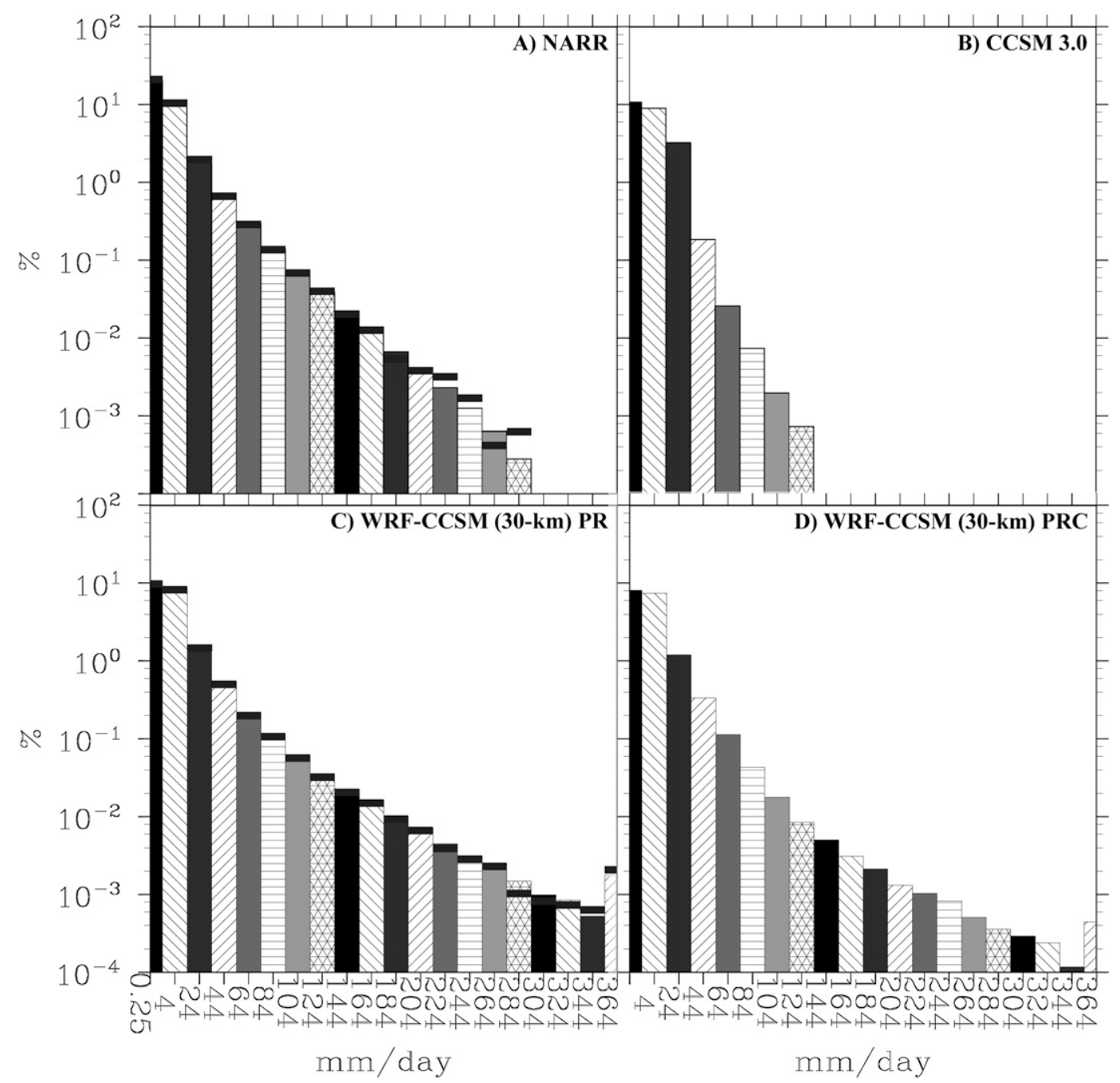

FIG. 4. The 1990-1999 MJJA frequency distribution for 6-h average precipitation rates (mm day ${ }^{-1}$ ) from (a) NARR, (b) CCSM, (c) WRF-CCSM (30-km nest) for the central U.S. region shown in Fig. 2d. (d) As in (c), but for the convective precipitation rate (PRC). The number under a given bar is the starting point value for that bin. Frequency is shown as the percent of 6-h periods with an average rate that falls into a given bin from all possible 6-h periods and grid points in the given region. Thick black lines included in (a) and (c) indicate the value that the distributions would have in a given bin if the included number of grid points was limited to the number available in the CCSM 3.0 (points nearest those in the CCSM 3.0 were used).

\section{d. Twentieth-century differences discussed}

As expected, the WRF driven by the NNRP is different from that using the CCSM. Although warm-season precipitation simulated by the WRF-CCSM is more realistic than that from the CCSM in many ways, the magnitude of the average MJJA precipitation is low. The WRF-CCSM is much drier than the WRF-NNRP over most large bodies of water and the western United States (though the latter is not particularly apparent in Fig. 2 since the west does not receive much warm-season rainfall). Over land east of the continental divide, the differences are generally smaller and less significant. However, the region that is particularly noteworthy in this domain is the northern plains, where the WRF-CCSM is significantly drier than the WRF-NNRP. This is reflected in the weak magnitude of the secondary maximum in Figs. $2 \mathrm{f}$ and $2 \mathrm{~g}$.

Given the identical model setup, these differences are clearly due to differences in initial and boundary conditions. It was found that the CCSM and the WRF-CCSM are deficient in low-to-midlevel moisture through most of the domain. For the central United States, this is clearly seen in the differences in average $850-\mathrm{hPa}$ specific humidity in Table 1 . The lack of atmospheric moisture likely plays a substantial role in the lower-than-average precipitation simulated by the WRF-CCSM. Inadequate low-level 

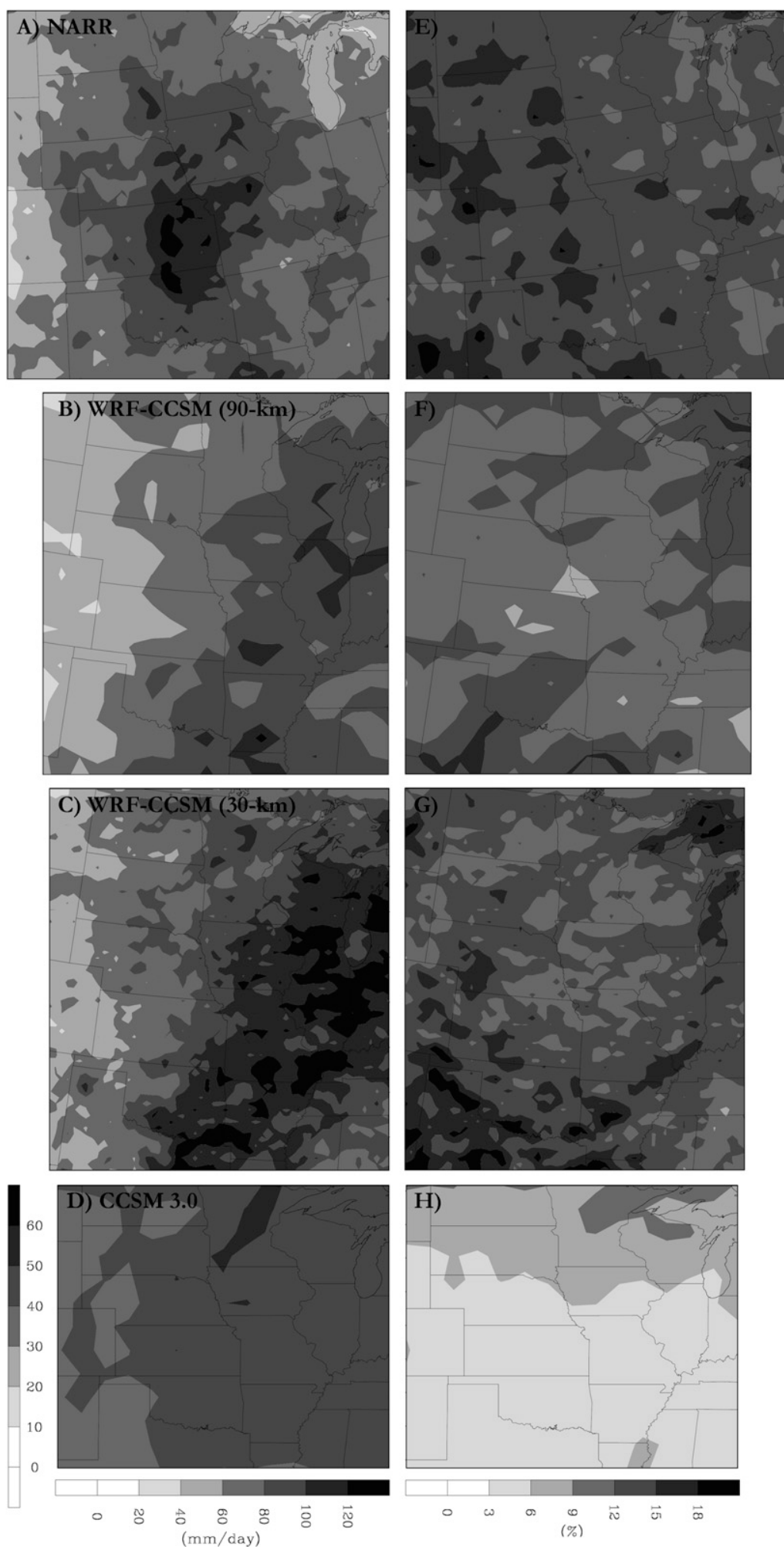

FIG. 5. (a)-(d) The 1990-1999 MJJA 99th percentile 6-h average precipitation rate $\left(\mathrm{mm} \mathrm{day}{ }^{-1}\right)$ from all values greater than a trace (defined at $0.25 \mathrm{~mm} \mathrm{day}^{-1}$ ) from (a) NARR, (b) WRF-CCSM (90-km domain), (c) WRF-CCSM (30-km nest), and (d) CCSM. (e)-(h) As in (a)-(d), but for the proportion of precipitation from events greater than the 99 th percentile (\%). Note that the contour scale in (d) is half of that used in (a)-(c) and is included to the left of (d). 


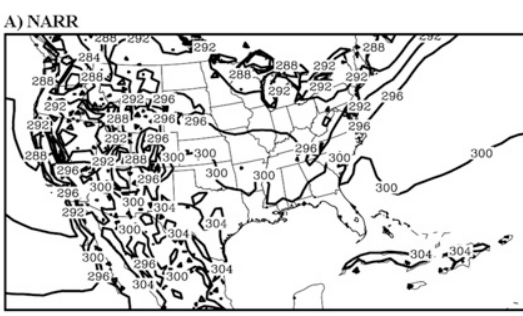

D) WRF-CCSM - WRF-NNRP

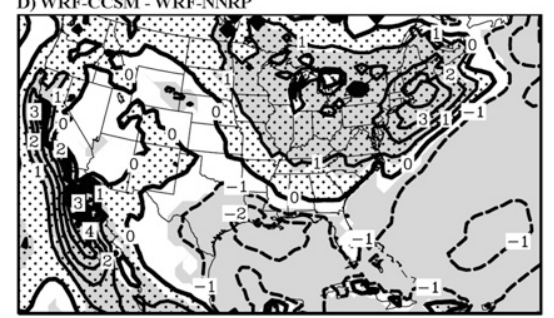

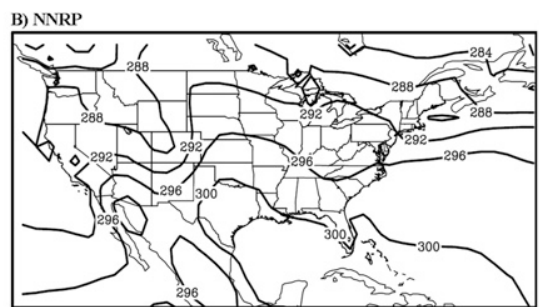

E) WRF-NNRP

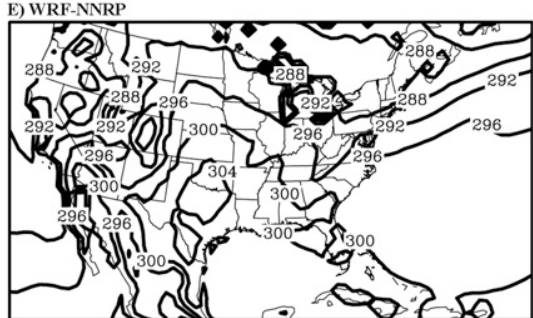

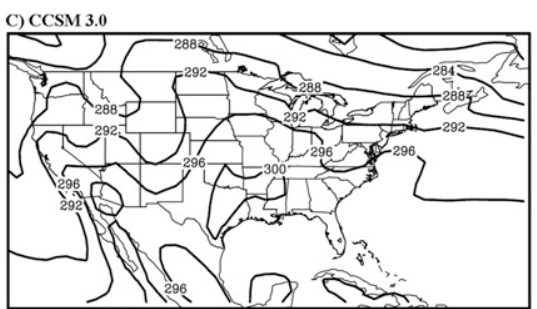

F) WRF-CCSM

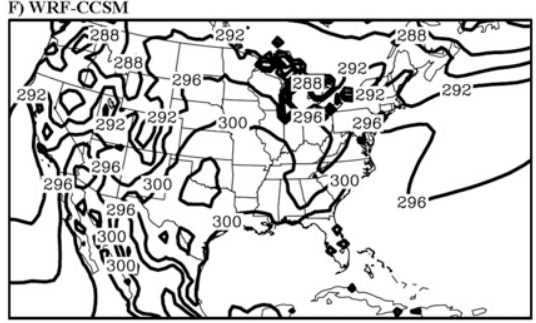

FIG. 6. The 1990-99 MJJA average 2-m temperature (K) from (a) NARR, (b) NNRP, (c) CCSM 3.0, (e) WRF-NNRP (90-km domain), and (f) WRF-CCSM (90-km domain), with contours every $4^{\circ}$. (d) The (f) - (e) difference, with contours every $1^{\circ}$; positive values are stippled, and shading indicates that the difference is statistically significant at the $10 \%$ level.

moisture also implies lower CAPE, which in turn would suggest less convective activity.

There are also issues related to the strength and direction of the LLJ in the WRF. However, the northward flow from the Gulf of Mexico in the WRF-CCSM is stronger than that in the WRF-NNRP (see Table 1, CUSLLJ statistics, for the central U.S. region expanded southward to $25^{\circ} \mathrm{N}$.), likely aiding its improvement over the CCSM in the magnitude of average 850-hPa specific humidity in the central United States. Nonetheless, both versions of the WRF simulate an LLJ that weakens and curves off to the east before reaching the full magnitude of its northward extent. ${ }^{3}$ This tendency is stronger in the WRF-NNRP, leading to the weak area-average $850-\mathrm{hPa}$ north-south wind component evident in Table 1.

The average precipitation values over the Southeast, Gulf of Mexico, Caribbean, and part of the Atlantic are also insufficient in the WRF-CCSM. Once again, the lack of low-level moisture in the WRF-CCSM likely facilitates this deficiency. While also influencing the moisture transport into the Great Plains, here, cool SSTs inherited from the CCSM probably have an influence as well. Figure $6 \mathrm{~d}$ illustrates that the WRF simulations of near-surface temperature are similar, except over water. Through the Atlantic and Gulf of Mexico, the WRF-CCSM is too cool, and off of the Pacific Coast and the NE coast, there are areas that are $2^{\circ}-6^{\circ}$ warmer than in the WRF-NNRP. ${ }^{4}$ These differences in temperature over water are the result of well-known biases in the CCSM-simulated SSTs, which

\footnotetext{
${ }^{3}$ This, in turn, may contribute to the excessive rainfall in the northeast as more moisture is transported out of the central United States.

${ }^{4}$ This could also be contributing to the wet bias in the Northeast.
}

are inherited in the WRF-CCSM as a lower boundary condition. Collins et al. (2006) show that on an annual average basis, CCSM SSTs in the Gulf are $0.5-2 \mathrm{~K}$ too cold, and up to $3 \mathrm{~K}$ too cold in the Caribbean, compared to observations. Collins et al. also discuss some of the related impacts this has on the atmosphere. As the NNRP system takes into account observed SSTs (Kalnay et al. 1996), the WRF-NNRP SSTs are likely to be a reasonable representation of actual SSTs, as they are updated every $6 \mathrm{~h}$ in the WRF from the NNRP.

Both WRF simulations also contain a dry bias in the southern plains that extends to the Texas-Louisiana Gulf Coast. This bias is similar to one seen in Diffenbaugh et al. (2006), using the third-generation Regional Climate Model (RegCM3) driven by the NNRP or the Community Atmosphere Model, version 3 (CAM3), though it is not necessarily caused by the same processes. While the WRF-CCSM is lacking in low-level moisture, the WRFNNRP is not; thus, this does not explain the lack of precipitation in this case. However, both WRF simulations are warmer than the NNRP suggests they should be in the south-central plains at the surface and at $850 \mathrm{hPa}$. The WRF-NNRP also generates a stronger anticyclonic circulation aloft over the southern plains than the NNRP. The same is true in the WRF-CCSM. The increased subsidence in this region, combined with the warmer lowlevel temperatures, would act to inhibit convection in this region, explaining the deficiency in precipitation here.

Additionally, the warm and dry bias may be exacerbated through interactions with the land surface. In the WRF-NNRP, soil moisture decreases more quickly through the MJJA season than it does in the NNRP, for example. Over the $30-\mathrm{km}$ domain, the fractional water 


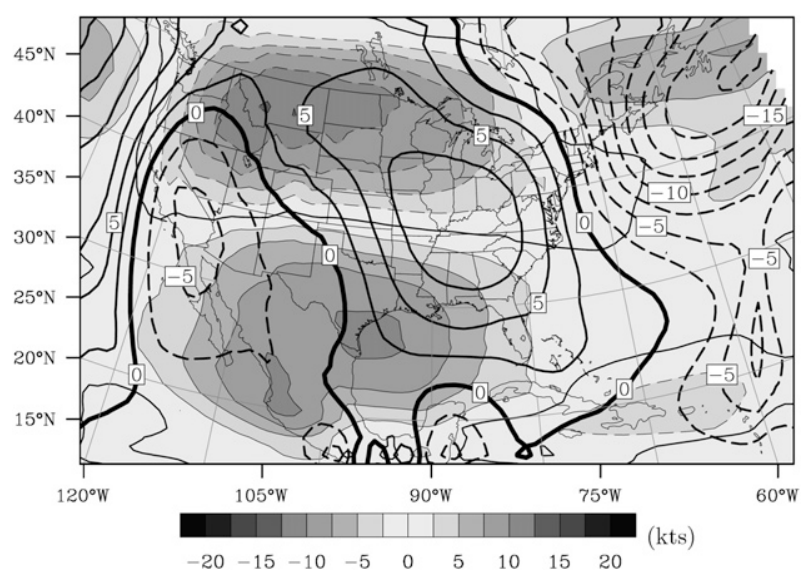

FIG. 7. The NNRP - WRF-NNRP difference for 1990-99 MJJA average 300-hPa U (shaded contours, negative contours dashed) and $V$ wind components (contours only, every $2.5 \mathrm{kt}$, negative dashed).

content of the $0-10-\mathrm{cm}$ soil layer decreases by $1.9 \%$ month $^{-1}$ in the WRF-NNRP, while it decreases by $0.8 \%$ month $^{-1}$ in the NNRP, on average. This could be due to the low bias in precipitation, but through land-atmosphere feedback mechanisms, it could also be contributing to the warm and dry bias.

However, the low bias in precipitation and the related model biases in temperature and pressure may be due to more than just errors in the representation of various physical processes in the WRF. As shown in Fig. 7, there appears to be a bias in the large-scale wave pattern between the NNRP and the WRF-NNRP. At most levels, this manifests itself as the excessive ridging near the center of the domain mentioned previously. It is possible that this bias is due to the accumulation of errors at the boundaries, especially the eastern exit boundary, and then the propagation of those errors back into the domain. This would not likely be a problem with short-term simulations, or if the simulations were initialized more frequently, but this large-scale bias does grow over time in the WRF and is clearly visible at the end of each 4-month simulation period. This problem is similar to one described by Miguez-Macho et al. (2005) in their month-long simulations using the Regional Atmospheric Modeling System (RAMS) forced by the NNRP.

There is no easy solution to this problem; thus, it remains unresolved in these experiments. ${ }^{5}$ However, it is most likely similar and internally consistent between the

\footnotetext{
${ }^{5}$ Applying some form of internal nudging may alleviate this problem, but could also have an undesirable impact on precipitation extremes (Alexandru et al. 2009). Variable resolution global models, such as OLAM (Walko and Avissar 2008), are also intended to reduce this problem.
}

twentieth- and twenty-first-century simulations. That is, while there are biases likely caused by this problem, they are contained in all of the WRF simulations, present and future.

\section{Regional climate projections}

Since it was demonstrated that the WRF is an effective tool for dynamically downscaling CCSM output from the twentieth century in order to obtain a better representation of precipitation, it was used to produce regional simulations of the later part of the twenty-first century. This section presents differences between the 1990s and the 2090s.

\section{a. Temperature}

The difference in 2-m temperature between these periods from the WRF-CCSM and the CCSM is shown in Fig. 8. At no point in either the $90-$ or the $30-\mathrm{km}$ domains does either the WRF-CCSM or the CCSM simulations show average cooling for the MJJA season. Both indicate an increase in average 2-m temperature of over $4 \mathrm{~K}$ for nearly the entire continental United States. This warming was found to be statistically significant at the $10 \%$ level at every grid point in both models and domains.

\section{b. Precipitation}

The WRF-CCSM projects a decrease in mean MJJA precipitation between the 1990s and the 2090s, as indicated in Figs. 9a and 9b. While there is a decrease of $10 \%$ or greater over most of the continental United States, this difference is only statistically significant (at the 10\% level) in certain regions; specifically, in the southeast, along the Gulf Coast into eastern Texas, and in parts of the central plains, certain Rocky Mountain states, and along the West Coast. This decrease in average precipitation over most of the continental United States for the summertime is consistent with projections from most climate models run in support of the IPCC AR4 (Christensen et al. 2007a); however, it is not consistent with the change in average MJJA precipitation in the CCSM between these two decades (Fig. 9c). The CCSM projects an increase of over $10 \%$ in mean MJJA precipitation in almost all continental regions of the United States except the northwest and Gulf Coast. Where the CCSM projects increases in average precipitation through the Southwest and Great Plains, the WRF-CCSM does produce less of a decrease or only a very slight increase. It is still interesting, however, that given the initial and boundary conditions from the CCSM, the WRF indicates a much drier summertime climate than its parent model for the future.

The decrease in mean MJJA precipitation in both domains is not accompanied by a decrease in the entire distribution of precipitation. It is mainly caused by 

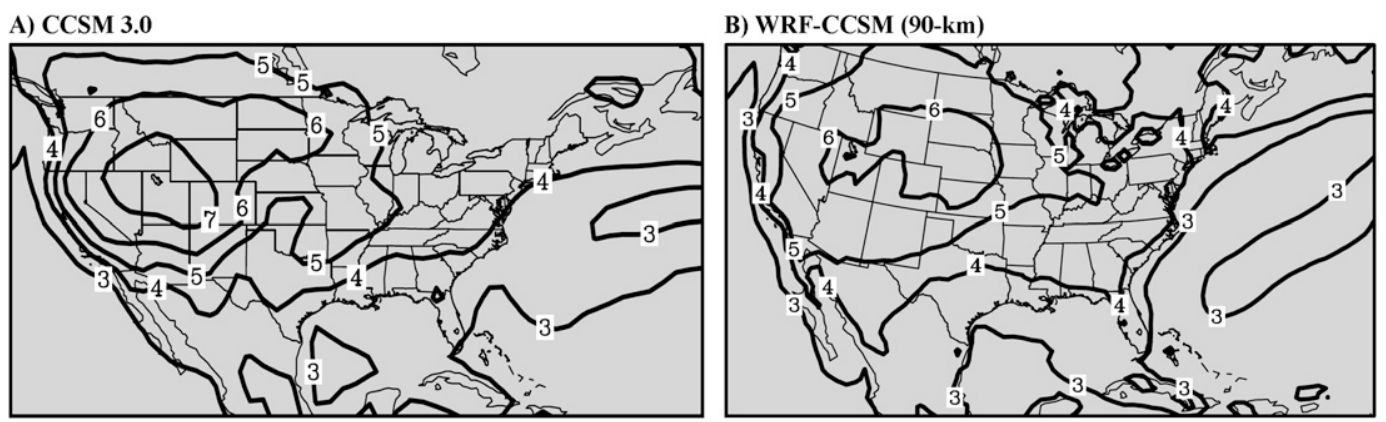

FIG. 8. Difference between the 2090-99 and 1990-99 MJJA average 2-m temperatures from (a) CCSM 3.0 and (b) WRF-CCSM (90-km domain). Gray-shaded areas indicate that the difference is significant at the $10 \%$ level.

a decrease in the occurrence of the light to moderate, but most frequent, rainfall events. This is illustrated for the central United States in Fig. 10. The change in the distribution of precipitation rates also indicates an increase in the much less frequent, but most intense precipitation events. For example, in Fig. 10a, we see that increases in frequency are statistically significant at the $10 \%$ level starting in the 264-284 mm day ${ }^{-1}$ bin. Occurrences of 6$\mathrm{h}$ average precipitation rates in this bin anywhere in the central United States increase by about $55 \%$ between the 1990s and the 2090s. However, in this region, the shift to more frequent extreme precipitation rates is obviously not enough to compensate for the decrease in lighter rates, resulting in the overall decrease in average precipitation.

The convective component of the precipitation distribution is included as Fig. 10b. It is clear that the changes in the distribution projected for the future are manifested mainly through convective precipitation, but not completely. The shift to increasing frequencies occurs at a much lower rate in the convective-only component, indicating that the resolved component does have an important influence on the overall projected frequency of total precipitation here. The differences between the total and convective precipitation distributions suggest a decrease in the frequency of the resolved precipitation component throughout most of the distribution.

There is also a slight overall increase projected in the magnitude of intense precipitation over the central United States. The average 99th percentile value for the $30-\mathrm{km}$ domain in the central United States increases from $88.1 \mathrm{~mm}$ day $^{-1}$ in the 1990 s to $94.41 \mathrm{~mm}$ day $^{-1}$ in the $2090 \mathrm{~s}$, an increase of $7.21 \%$. For more common, yet still heavy, precipitation events, the WRF-CCSM also shows slight increases in magnitude in the central United States. The regional average increase in the 90th percentile 6 -h average precipitation rate is $1.11 \%$ in the central United States using the $30-\mathrm{km}$ nest simulations. For less common events, the increase in magnitude is greater. The upper 0.3 th percentile is projected to increase by $14.3 \%$ and the upper 0.1 percentile by $20.8 \%$ (defined as very heavy and extreme, respectively, by Groisman et al. (2005), who also defined the upper 10th percentile as heavy).

Using the entire distribution of 6-hourly average rates from every point in the central United States (i.e., those used in Fig. 10a and excluding values less than a trace), we can more easily illustrate that although the magnitude of heavy to very heavy events might increase, the frequency of those events may still decrease. This is the case for the 90th percentile value as well as the 99th percentile value. The latter, for example, increases from 94.8 to $103.0 \mathrm{~mm} \mathrm{day}^{-1}$, but these values are located in a part of the distribution that exhibits a decrease in frequency of about $25 \%$. Ultimately, it is only the very heavy to extreme events that increase in both magnitude and frequency. The 99.7th percentile value increases in magnitude from 149 to $178 \mathrm{~mm} \mathrm{day}^{-1}$, and this is the point in the distribution where values begin to show an increase in frequency. The 99.9th percentile value increases in magnitude from 208 to $258 \mathrm{~mm} \mathrm{day}^{-1}$, or $24.1 \%$, and spans bins that exhibit clear increases in frequency.

Thus, even though there are increases in the magnitude of heavy precipitation rates, there is no increase in the frequency of those events until they reach a rate that might be defined as very heavy. Either way, these are events that are more likely to be disruptive and have a greater impact.

Another, more simplistic way to look at what happens to precipitation in the future is to examine the change in the number of wet and dry periods (or the number of periods contributing to the total precipitation for a given time span, or not), the number of consecutive wet and dry periods, and the average intensity of precipitation when it does rain (Frich et al. 2002; Sun et al. 2006). Both are usually calculated from daily precipitation data, and the latter are known as the simple daily intensity index (SDII): the total precipitation from wet days over a period of time divided by the number of wet days in that period [where wet days are defined as having precipitation greater than 


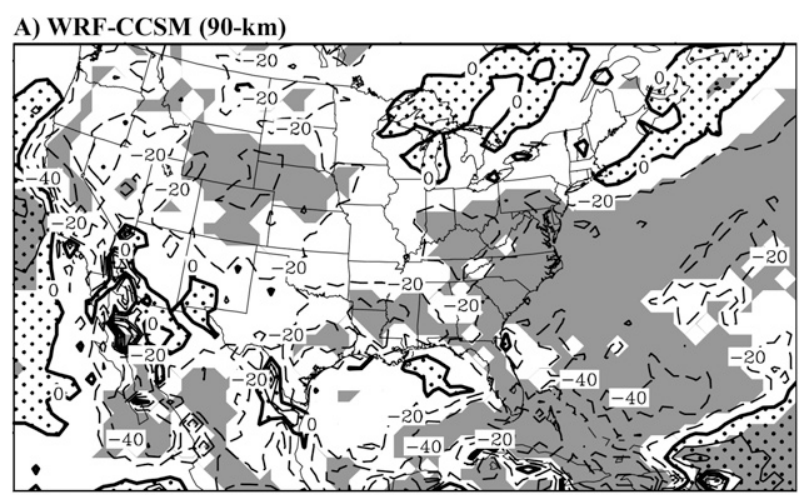

B) WRF-CCSM (30-km)

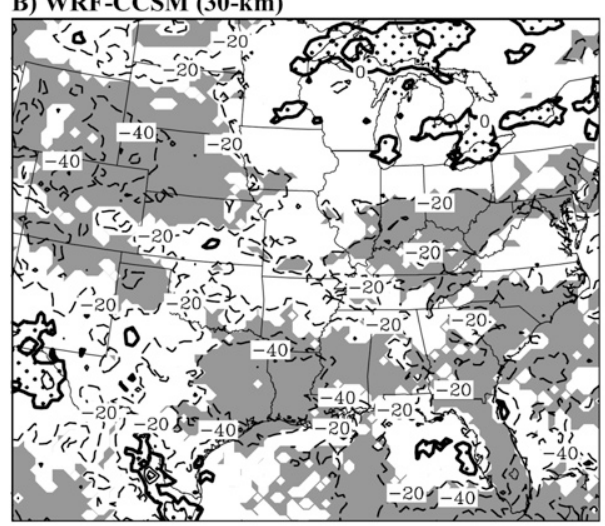

C) CCSM 3.0

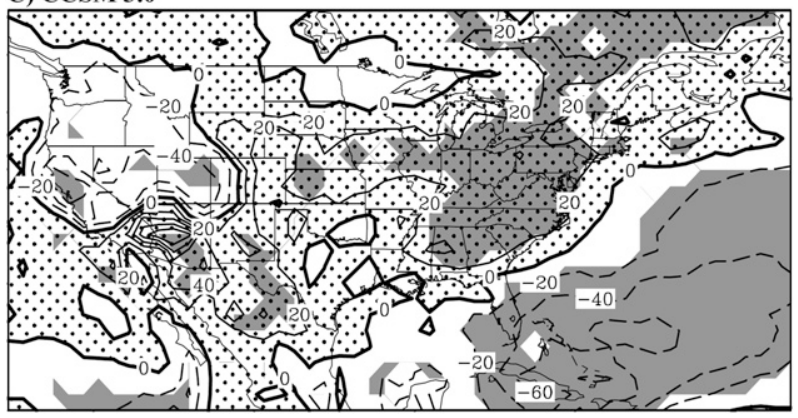

FIG. 9. Percent difference between 2090-99 and 1990-99 MJJA average precipitation results from (a) WRF-CCSM (90-km domain), (b) WRF-CCSM (30-km nest), and (c) CCSM ( $20 \%$ contour interval; positive areas stippled, negative contours dashed). Gray-shaded areas indicate that the difference is significant at the $10 \%$ level.

$1 \mathrm{~mm} \mathrm{day}^{-1}$; Frich et al. (2002)]. Here, these metrics are applied to 6-h-average precipitation rates to better understand the changes in the frequency and intensity of precipitation seen above. Wet periods are defined at every grid point as 6-h rates greater than a trace (previously defined at $0.25 \mathrm{~mm} \mathrm{day}^{-1}$ ); all others are defined as dry periods.

In the 30-km WRF-CCSM simulation over the central U.S. region, there is a decrease in MJJA average precipitation, as illustrated in Fig. 9. The total percent decrease in this region is approximately $18.2 \%$. As summarized in
Table 2, between the 1990s and 2090s, the number of wet periods (NW6) decreases by $22.7 \%$ while the number dry periods (ND6) increases by $5.8 \%$. The simple intensity index for 6-h periods (S6II) increases by approximately $6.2 \%$. This indicates that periods of rain are fewer and farther between, but that when it does rain, it is more intense. The slight increase in intensity when it does precipitate is not enough to compensate for the decrease in the number of rain periods, leading to an overall decrease in average precipitation for the region.

The increase in the number of dry periods and the decrease in the number of wet periods also suggest an increase in the number of consecutive dry periods and/or dry days. Accordingly, there is a $23.7 \%$ increase in the average number of consecutive dry 6 -h periods (CD6 avg), and a $9.5 \%$ decrease in the average number of consecutive wet 6-h periods (CW6 avg). The increases and decreases in consecutive dry and wet periods are even more pronounced at more extreme lengths, as indicated in Table 2 for 99th percentile events (CD6 99th and CW6 99th). In short, dry spells are projected to be around $32.7 \%$ longer and wet spells to be $12.5 \%$ shorter. Therefore, the overall results from the WRFCCSM suggest for the central United States an increase in the frequency of droughts and floods, associated with longer dry spells and the increased frequency of heavy precipitation.

A similar analysis can be completed for the CCSM and is included in Table 2. In the central United States, the CCSM simulates an increase in average precipitation of about $15 \%$. The direction of change in the number of wet and dry periods is the same as in the WRF-CCSM, but lesser in magnitude, at $-2.3 \%$ and $+0.7 \%$, respectively. However, combined with an increase in S6II of about $17.9 \%$, it may be raining slightly less often, but the increase in the intensity of precipitation when it does rain is enough to compensate for this, leading to an overall increase in precipitation between the 1990s and the 2090s in MJJA. Changes in the number of consecutive dry and wet days are much smaller than those projected by the WRFCCSM for this region, at $6.2 \%$ and $1.5 \%$, respectively. Changes in the 99th percentile CD6 and CW6 are, as expected, larger, but do not necessarily agree in sign with the projections from the WRF-CCSM. The CCSM instead projects that when there are wet spells of extreme length that they will be longer, with the same applying to dry spells, as shown in Table 2.

\section{LIMITS}

In theory, the changes projected for the magnitude of heavy to extreme precipitation events during the central U.S. warm season may be constrained. Following the Clausius-Clapeyron relationship, for every degree of 

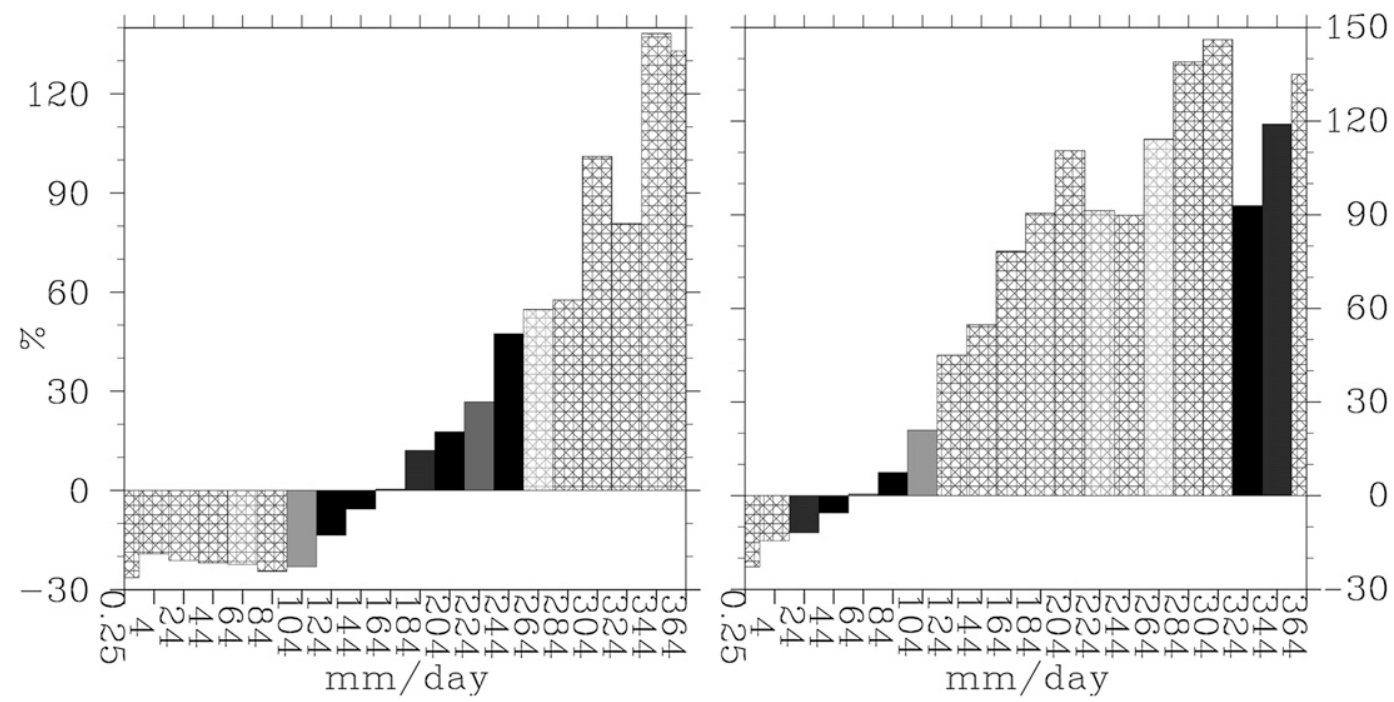

FIG. 10. Percent difference between the 2090-99 and 1990-99 MJJA (left) 6-h average precipitation rate and (right) convective precipitation rate frequency distribution from the WRF-CCSM 30-km nest for the central United States. Hatching indicates that the difference is significant at the $10 \%$ level.

temperature rise, the saturated vapor pressure rises by $6.5 \%$ [for a global mean temperature of $14.2^{\circ} \mathrm{C}$; Boer (1993)]. This presents an approximate upper bound on changes in the uppermost quantile of precipitation globally, though exceeding it would be possible with positive feedbacks, such as those that might occur with latent heating. For the central United States, with a 5.3-K increase in average projected temperature, the magnitude of increases in precipitation would be limited to approximately $34.5 \%$. Given the results presented in Fig. 11 , projections from the WRF-CCSM for intense precipitation in this region do appear to be constrained by the global Clausius-Clapeyron-derived limit.

\section{c. Understanding the WRF projections}

As with temperature, the results from the WRF-CCSM for MJJA average precipitation are consistent with those from the IPCC AR4 (Christensen et al. 2007a, section 11.5.3.2, Fig. 11.12), in that there is an average decrease over most of the country. As mentioned, however, this result is not consistent with that from the CCSM. This is not the first study to show a change in an average quantity from a regional model that is in a direction opposition to that from the parent GCM. Han and Roads (2004) and Pan et al. (2004) both encountered this in simulations over the United States using different RCMs (and forcing GCMs) in precipitation or temperature, respectively, and both show increased skill in the regional model over that from the driving global model or reanalysis. However, understanding these differences is important.

The decrease in average precipitation rate projected by the WRF-CCSM occurs despite an increase in average mixing ratio and vertically integrated moisture content (not shown) in both the CCSM and the WRF-CCSM. Discrepancies similar to those seen in the precipitation projection occur in evaporation rate and precipitation minus evaporation (P-E) though. To demonstrate why this could occur, the central United States was examined in more detail.

For the central U.S. region, the CCSM shows an approximately $14.3 \%$ increase in average precipitation rate, a $13.9 \%$ increase in average evaporation rate, and an increase in P-E from -0.090 to $-0.071 \mathrm{~mm} \mathrm{day}^{-1}$. $^{6}$ The WRF-CCSM, on the other hand, shows a decrease in average precipitation rate of about $19.5 \%$, a decrease in evaporation rate of $10.0 \%$, and a decrease in $\mathrm{P}-\mathrm{E}$ from -0.211 to $-0.388 \mathrm{~mm} \mathrm{day}^{-1}$. $^{7}$ The area of significant decrease (increase) in the central plains in precipitation and evaporation in the WRF-CCSM (CCSM) is located near the northern terminus of the southerly LLJ at

\footnotetext{
${ }^{6}$ The $\mathrm{P}-\mathrm{E}$ in the CCSM is positive over almost all of the central U.S. region. It is slightly negative in the quoted regional average because $\mathrm{P}-\mathrm{E}$ over the Great Lakes is strongly negative relative to the rest of the region; this is because the CCSM simulations produce a large amount of surface latent heat flux over the Great Lakes and, therefore, a large amount of evaporation since it is calculated from the surface latent heat flux. The WRF-CCSM, on the other hand, simulates a relative minimum in evaporation over the Great Lakes, and while P-E is positive over the Great Lakes, it is overcome by negative values in $\mathrm{P}-\mathrm{E}$ of relatively the same magnitude over the majority of the central United States in the regional average. This does not impact the increase in $\mathrm{P}-\mathrm{E}$ projected by the CCSM; the change is positive over most of the region.

${ }^{7}$ WRF-CCSM values given were calculated using the $30-\mathrm{km}$ simulations.
} 
TABLE 2. Simple precipitation statistics for the central United States from the WRF-CCSM 30-km domain, CCSM, and the NARR for MJJA 1990-99, and the percent change in those statistics in MJJA of 2090-99.

\begin{tabular}{|c|c|c|c|c|c|c|c|c|}
\hline & Avg & NW6 & ND6 & S6II & CD6 avg & CW6 avg & CD6 99th & CW6 99th \\
\hline Current & $\left(\mathrm{mm}\right.$ day $\left.^{-1}\right)$ & (Fractional) & (Fractional) & $\left(\mathrm{mm} \mathrm{day}{ }^{-1}\right)$ & (No.) & (No.) & (No.) & (No.) \\
\hline NARR & 2.9 & 0.35 & 0.65 & 8.3 & 4.1 & 2.2 & 9.0 & 5.0 \\
\hline CCSM & 2.5 & 0.23 & 0.77 & 10.6 & 7.7 & 2.5 & 62.0 & 13.0 \\
\hline WRF-CCSM & 2.3 & 0.20 & 0.80 & 11.2 & 8.0 & 2.1 & 49.0 & 8.0 \\
\hline Future & \multicolumn{8}{|c|}{ (Percent difference...) } \\
\hline CCSM & 15.1 & -2.3 & 0.7 & 17.9 & 6.2 & 1.5 & 12.9 & 15.4 \\
\hline WRF-CCSM & -18.2 & -22.7 & 5.8 & 6.2 & 23.7 & -9.5 & 32.7 & -12.5 \\
\hline
\end{tabular}

$850 \mathrm{hPa}$. Given an increase in SSTs in the Gulf of Mexico in the 2090s, it is not illogical for precipitation to increase in this region. An increase in Gulf of Mexico SSTs would likely lead to an increase in precipitable water over the Gulf, promoting low-level moisture convergence in the central United States, which, in turn, is favorable for convection. The increase in moisture convergence in this region is where the CCSM and the WRF-CCSM differ, however.

The vertically integrated transport of moisture indicates an increase in moisture transport in both the CCSM and the WRF-CCSM in the central United States (Fig. 12). However, the net moisture convergencedivergence for this region differs. According to observations and several reanalyses, including the NNRP, the central United States should exhibit summertime moisture flux convergence (Roads et al. 1994; Ruiz-Barradas and Nigam 2005, 2006). The CCSM does, and, as is necessary considering the positive change in $\mathrm{P}-\mathrm{E}$, it also projects an increase in moisture convergence for this region of approximately $47 \%$. The WRF-CCSM, on the other hand, simulates net moisture divergence for the central United States and an increase in future moisture divergence of about $152 \%,{ }^{8}$ consistent with its decrease in P-E. The WRF-NNRP also simulates the net moisture divergence for the central United States, despite the NNRP containing the opposite. The net transport of moisture out of the eastern boundary of the central U.S. region is larger in the WRF-CCSM than in the CCSM, relative to the net transport into the region at the southern boundary. This difference increases in the future in the WRF-CCSM. Furthermore, the net transport from the south increases in both, but that increase is greater in the CCSM, leading to the differences between the two. The root cause of this problem has not been established, and is outside the scope of this project. There could be a number of contributing

\footnotetext{
${ }^{8}$ Values of divergence were calculated using Gauss's divergence theorem around the entire central U.S. region using data from the $30-\mathrm{km}$ nest for the WRF simulations.
}

factors, but this is likely related to the issues mentioned previously with the LLJ in the WRF.

\section{Summary and final discussion}

An analysis of late-twentieth- and late-twenty-firstcentury warm-season precipitation patterns simulated by the WRF run as a nested regional climate model has been presented. In summary, these are some of the main findings and questions that have been answered by this work:

- The WRF was found to improve upon some of the characteristics of U.S. warm-season precipitation over that from its driving reanalysis and global climate model. Specifically, the WRF improved the realism of the diurnal cycle (in the $30-\mathrm{km}$ nest only), the spatial distribution, the magnitude of heavy 6-h events, and the frequency distribution of precipitation over the central United States.

- Overall, decreases in average MJJA precipitation were projected over most of the United States by the end of the twenty-first century. Significant decreases in the frequency of all but the very heavy 6 -h precipitation events (those over the 99.7th percentile), significant

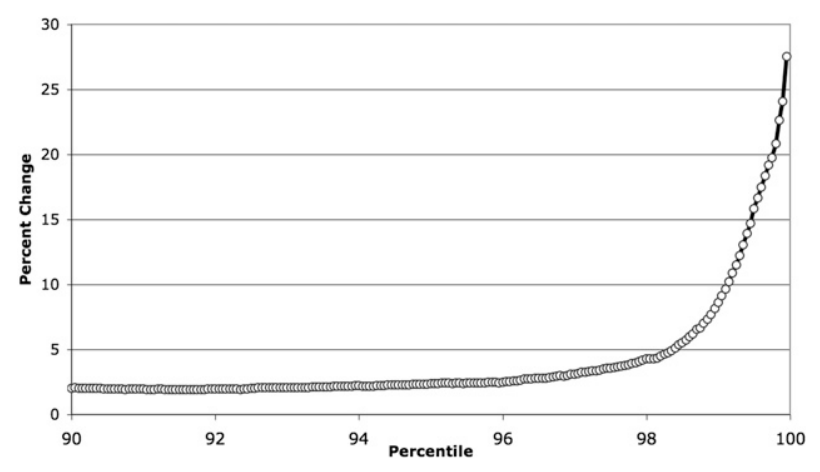

FIG. 11. Percent change in MJJA precipitation rate percentiles from the 90th to the 99.95th between 1990 and 1999 and 2090 and 2099 for the central U.S. region. Empty circles are placed every five-hundredths of a percentile. 
A) CCSM 3.0 1990-1999

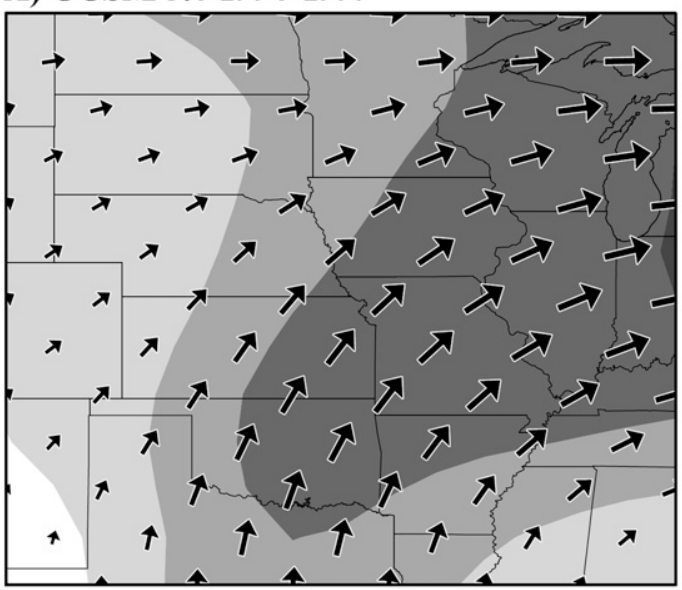

B) WRF-CCSM (30-km) 1990-1999

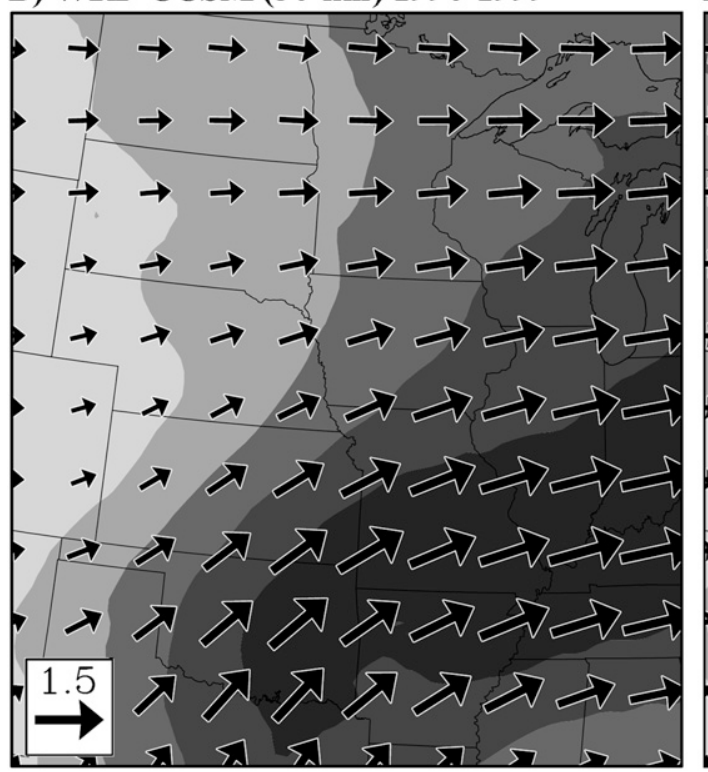

2090-2099

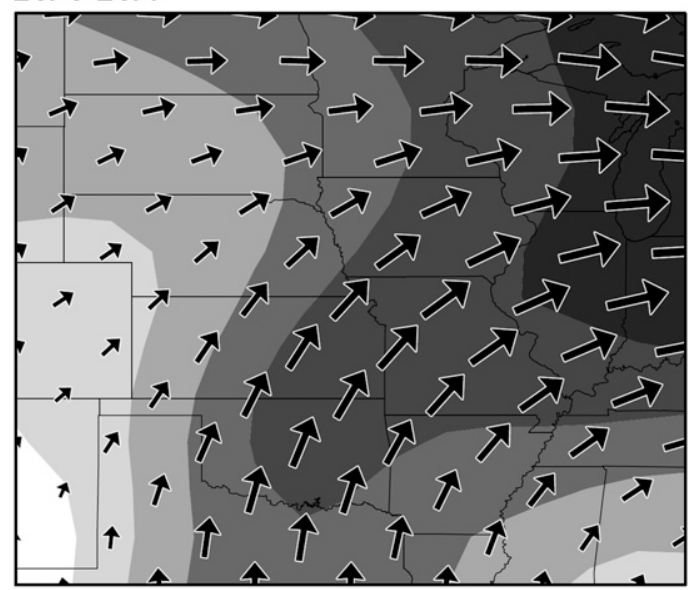

\section{0-2099}

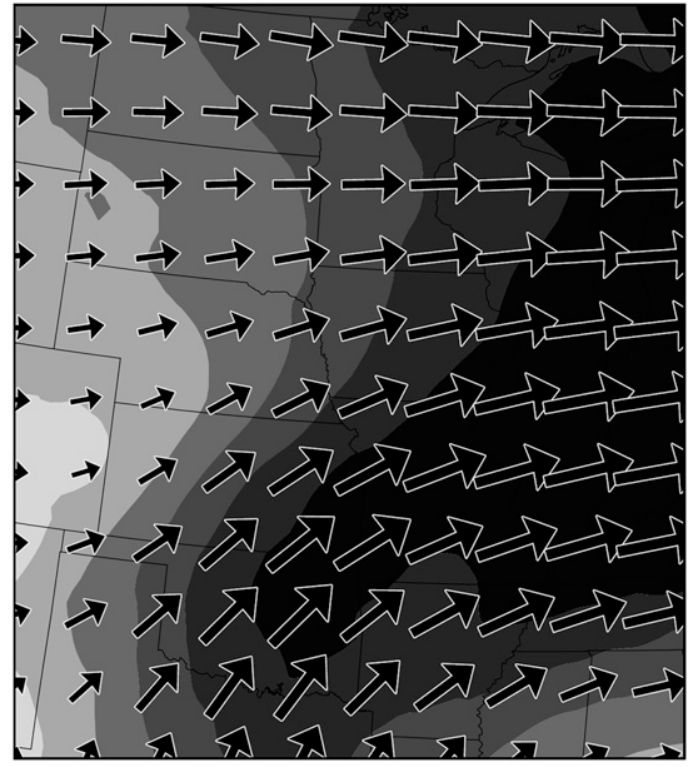

$(\mathrm{g} \mathrm{kg}-1 \mathrm{~m} \mathrm{~s}-1)$

FIG. 12. The (left) 1990-99 and (right) 2090-2099 MJJA average transport of water vapor mixing ratio $\left(\mathrm{g} \mathrm{kg}^{-1} \mathrm{~m} \mathrm{~s}^{-1}\right.$ ) in the central United States from (a) CCSM 3.0 and (b) the WRF-CCSM 30-km nest. Reference vector inset in (b) is set at $1.5 \mathrm{~g} \mathrm{~kg}^{-1} \mathrm{~m} \mathrm{~s}^{-1}$.

increases in the frequency of those extreme events, increases in the intensity of both heavy precipitation events and in the general intensity of rain when it does fall, decreases in the number of 6-h periods with rainfall, and an increase in the number of 6-h periods without rainfall were also projected by the WRFCCSM for the central United States. This suggests an increase in the frequency of both flooding and drought for the late twenty-first century.

- Issues regarding the differences between the WRFNNRP and the WRF-CCSM and their forcing reanalysis or GCM were also discussed. It was explained that the WRF-CCSM is subject to biases from the CCSM, like SSTs that are too cold and insufficient low-level moisture. Both the WRF-CCSM and the WRF-NNRP are also subject to internal biases, which will hopefully be improved upon in the future. Despite this, they still produce reasonable warm-season climate simulations.

The ability of the WRF to simulate some aspects of warm-season precipitation over the United States at a $30-\mathrm{km}$ resolution better than most current global climate 
models may be expected given its increase in resolution and the less simplistic nature of some of its parameterizations, but this may not have been the result. There is still room for improvement, and simulation of warm-season precipitation remains a challenge. As noted in Christensen et al. (2007a, p. 889), using a regional model for the U.S. warm season does not guarantee a better response just because it has a higher resolution.

Though it did produce precipitation simulations that were more realistic than those from a GCM in many ways, further work will be required to remove some of the internally rooted model bias found in the version of the WRF applied herein. There is also a potential error in radiation not previously mentioned in the simulations of the future. That is, the simulations for the future indirectly receive the impacts of changes in the concentration of various atmospheric constituents (e.g., greenhouse gases) through the initial and boundary conditions from the CCSM. Direct changes in these quantities in the WRF model are not included; that is, the concentrations are the same in the present as in the future in the WRF. This would lead to a gradual and slight cooling of the troposphere over time in the late-twenty-first century simulations. However, this is likely balanced by the continual advection of a largescale environment that includes the change in concentrations via the boundary conditions. Further work will be needed to examine the degree to which this is balanced or not and to which the tropospheric warming in the WRF may be underestimated because of this.

More simulated years per century would also help strengthen the analysis of average and extreme precipitation events completed in this study, particularly since the latter are rare and relatively few are produced per grid point per decade; they are even subject to uncertainty in observational studies. Additionally, this study produces quantitative results regarding the impacts of climate change on precipitation in the central United States, but the results are only from one version of one regional model given conditions from one global model. A greater ensemble of nested regional simulations based on changes in WRF physics, the use of other regional models, other driving models, and/or other emission scenarios would help quantify more of the uncertainty in the projections presented and provide a greater range of expected outcomes. Coordinated projects that are addressing a number of these issues through an ensemble approach have been completed or are under way; such as the North American Regional Climate Change Assessment Program (NARCCAP; Mearns et al. 2009), a Coordinated Regional Climate Downscaling Experiment (CORDEX; Giorgi et al. 2009), the Prediction of Regional Scenarios and Uncertainties for Defining European Climate Change Risks and Effects project (PRUDENCE;
Christensen et al. 2007b), and the ENSEMBLES project (van der Linden and Mitchell 2009). It will be especially interesting to see if the NARCCAP simulations driven by the CCSM3.0 using three different regional models produce similar results to those shown here for future precipitation, and if so, why. However, this is all beyond the range of the current study.

Despite its limitations, this current work is a significant contribution to a growing number of regional climate studies; it provides a well-scrutinized ensemble member that can more completely address the impacts of climate change on warm-season precipitation over the United States. It is planned to continue further investigation along these lines.

Acknowledgments. This work was completed as part of the first author's dissertation at the University of Oklahoma. She would like to thank everyone who assisted in the process. Support has been provided by the Gary Comer Science and Education Foundation. David Karoly is the recipient of an Australian Research Council Federation fellowship (Project FF0668679). The authors would also like to thank the four anonymous reviewers for their comments on the manuscript. Additionally, we would like to acknowledge the support of NCAR and NSF. NARR data were obtained from the NCEP Web site (http://wwwt.emc.ncep.noaa.gov/mmb/rreanl/), the CPC hourly precipitation analysis is available from NOAA (http://www.esrl.noaa.gov/psd/data/gridded/data.cpc_hour. html), NNRP data were obtained from the NCAR Computational and Information Systems Laboratory Research Data Archive (http://dss.ucar.edu/datasets/ds090.0/), and output from the Community Climate System Model is available at the Earth System Grid (http://www. earthsystemgrid.org).

\section{REFERENCES}

Alexandru, A., R. de Elia, R. Laprise, L. Separovic, and S. Biner, 2009: Sensitivity of regional climate model simulations to largescale nudging parameters. Mon. Wea. Rev., 137, 1666-1686.

Anderson, C. J., and Coauthors, 2003: Hydrological processes in regional climate model simulations of the central United States flood of June-July 1993. J. Hydrometeor., 4, 584-598.

Augustine, J. A., and F. Caracena, 1994: Lower-tropospheric precursors to nocturnal MCS development over the central United States. Wea. Forecasting, 9, 116-135.

Bechtold, P., J. P. Chaboureau, A. C. M. Beljaars, A. K. Betts, M. Köhler, M. Miller, and J. L. Redelsperger, 2004: The simulation of the diurnal cycle of convective precipitation over land in global models. Quart. J. Roy. Meteor. Soc., 130, 31193137.

Boer, G. J., 1993: Climate change and the regulation of the surface moisture and energy budgets. Climate Dyn., 8, 225-239.

Bukovsky, M. S., and D. J. Karoly, 2007: A brief evaluation of precipitation from the North American Regional Reanalysis. J. Hydrometeor., 8, 837-846. 
— and - 2009: Precipitation simulations using the WRF as a nested regional climate model.J. Appl. Meteor. Climatol., 48, 2152-2156.

Christensen, J. H., and Coauthors, 2007a: Regional climate projections. Climate Change 2007: The Physical Science Basis, S. Solomon et al., Eds., Cambridge University Press, 847-940.

— , T. R. Carter, M. Rummukainen, and G. Amanatidis, 2007b: Evaluating the performance and utility of regional climate models: The PRUDENCE project. Climatic Change, 81, doi:10.1007/s10584-006-9211-6.

Collins, W. D., 2001: Parameterization of generalized cloud overlap for radiative calculations in general circulation models. J. Atmos. Sci., 58, 3224-3242.

— - J. K. Hackney, and D. P. Edwards, 2002: A new parameterization for infrared emission and absorption by water vapor in the National Center for Atmospheric Research Community Atmosphere Model. J. Geophys. Res., 107, 4664, doi:10.1029/ 2001JD001365.

- and Coauthors, 2006: The Community Climate System Model: CCSM3. J. Climate, 19, 2122-2143.

Dai, A., 1999: Recent changes in the diurnal cycle of precipitation over the United States. Geophys. Res. Lett., 26, 341-344.

_ 2006: Precipitation characteristics in 18 coupled climate models. J. Climate, 19, 4605-4630.

Davis, C. A., K. W. Manning, R. E. Carbone, S. B. Trier, and J. D. Tuttle, 2003: Coherence of warm-season continental rainfall in numerical weather prediction models. Mon. Wea. Rev., 131, 2667-2679.

Diffenbaugh, N. S., M. Ashfaq, B. Shuman, J. W. Williams, and P. J. Bartlein, 2006: Summer aridity in the United States: Response to mid-Holocene changes in insolation and sea surface temperature. Geophys. Res. Lett., 33, L22712, doi:10.1029/ 2006GL028012.

Duffy, P. B., B. Govindasamy, J. P. Iorio, J. Milovich, K. R. Sperber, K. E. Taylor, M. F. Wehner, and S. L. Thompson, 2003: Highresolution simulations of global climate. Part 1: Present climate. Climate Dyn., 21, 371-390.

Efron, B., and R. Tibshirani, 1993: An Introduction to the Bootstrap. Chapman and Hall/CRC, $450 \mathrm{pp}$.

Ek, M. B., K. E. Mitchell, Y. Lin, P. Grunmann, E. Rodgers, G. Gayno, and V. Koren, 2003: Implementation of the upgraded Noah land-surface model in the NCEP operational mesoscale Eta Model. J. Geophys. Res., 108, 8851, doi:10.1029/ 2002JD003296.

Fowler, H. J., M. Ekström, C. G. Kilsby, and P. D. Jones, 2005: New estimates of future changes in extreme rainfall across the UK using regional climate model integrations. 1. Assessment of control climate. J. Hydrol., 300, 212-233.

Frei, C., R. Schöll, S. Fukutome, J. Schmidli, and P. L. Vidale, 2006: Future change of precipitation extremes in Europe: An intercomparison of scenarios from regional climate models. J. Geophys. Res., 111, D06105, doi:10.1029/2005JD005965.

Frich, P., L. V. Alexander, P. Della-Marta, B. Gleason, M. Haylock, A. M. G. K. Tank, and T. Peterson, 2002: Observed coherent changes in climatic extremes during the second half of the twentieth century. Climate Res., 19, 193-212.

Garratt, J. R., P. B. Krummel, and E. A. Kowalczyk, 1993: The surfaceenergy balance at local and regional scales-A comparison of general circulation model results with observations. J. Climate, 6, 1090-1109.

Giorgi, F., C. Jones, and G. R. Asrar, 2009: Addressing climate information needs at the regional level: The CORDEX framework. WMO Bull., 58, 175-183.
Groisman, P. Ya., R. S. Bradley, and B. Sun, 2000: The relationship of cloud cover to near-surface temperature and humidity: Comparison of GCM simulations with empirical data. J. Climate, 13, 1858-1878.

, R. W. Knight, D. R. Easterling, T. R. Karl, G. C. Hegerl, and V. N. Razuvaev, 2005: Trends in intense precipitation. J. Climate, 18, 1326-1350.

Han, J., and J. O. Roads, 2004: U.S. climate sensitivity simulated with the NCEP Regional Spectral Model. Climatic Change, 62, $115-154$.

Higgins, R. W., J. E. Janowiak, and Y. P. Yao, 1996: A gridded hourly precipitation data base for the United States (19631993). NCEP/Climate Prediction Center Atlas 1, 47 pp.

Hong, S. Y., J. Dudhia, and S. H. Chen, 2004: A revised approach to ice microphysical processes for the bulk parameterization of clouds and precipitation. Mon. Wea. Rev., 132, 103-120.

—, Y. Noh, and J. Dudhia, 2006: A new vertical diffusion package with an explicit treatment of entrainment processes. Mon. Wea. Rev., 134, 2318-2341.

Kain, J. S., 2004: The Kain-Fritsch convective parameterization: An update. J. Appl. Meteor., 43, 170-181.

_ , and J. M. Fritsch, 1992: The role of the convective "trigger function" in numerical forecasts of mesoscale convective systems Meteor. Atmos. Phys., 49, 93-106.

Kalnay, E., and Coauthors, 1996: The NCEP/NCAR 40-Year Reanalysis Project. Bull. Amer. Meteor. Soc., 77, 437-471.

Kiehl, J. T., J. J. Hack, G. B. Bonan, B. A. Boville, D. L. Williamson, and P. J. Rasch, 1998: The National Center for Atmospheric Research Community Climate Model: CCM3. J. Climate, 11, 1131-1149.

Leung, L. R., and Y. Qian, 2009: Atmospheric rivers induced heavy precipitation and flooding in the western U.S. simulated by the WRF Regional Climate Model. Geophys. Res. Lett., 36, L03820, doi:10.1029/2008GL036445.

_ _ _ , and X. Bian, 2003: Hydroclimate of the western United States based on observations and regional climate simulation of 1981-2000. Part I: Seasonal statistics. J. Climate, 16, 18921911.

Liang, X. Z., K. E. Kunkel, and A. N. Samel, 2001: Development of a regional climate model for U.S. Midwest applications. Part I: Sensitivity to buffer zone treatment. J. Climate, 14, 4363-4378.

, L. Li, A. Dai, and K. E. Kunkel, 2004a: Regional climate model simulation of summer precipitation diurnal cycle over the United States. Geophys. Res. Lett., 31, L24208, doi:10.129/ 2004GL021054.

$\longrightarrow,-$, K. E. Kunkel, M. Ting, and J. X. L. Wang, 2004b: Regional climate model simulation of U.S. precipitation during 1982-2002. Part I: Annual cycle. J. Climate, 17, 3510-3529.

, J. Pan, J. Zhu, K. E. Kunkel, J. X. L. Wang, and A. Dai, 2006: Regional climate model downscaling of the U.S. summer climate and future change. J. Geophys. Res., 111, D10108, doi:10.1029/2005JD006685.

Lin, X., D. A. Randall, and L. D. Fowler, 2000: Diurnal variability of the hydrological cycle and radiative fluxes: Comparisons between observations and a GCM. J. Climate, 13, 4159-4179.

Mearns, L. A., W. Gutowski, R. Jones, R. Leung, S. McGinnis, A. Nunes, and Y. Qian, 2009: A regional climate change assessment program for North America. Eos, Trans. Amer. Geophys. Union, 90, 311.

Miguez-Macho, G., G. L. Stenchikov, and A. Robock, 2005: Regional climate simulations over North America: Interaction of 
local processes with improved large-scale flow. J. Climate, 18, $1227-1246$.

Nakicenovic, N., and Coauthors, 2000: Special Report on Emissions Scenarios. Cambridge University Press, $432 \mathrm{pp}$.

Pan, Z., J. H. Christensen, R. W. Arritt, W. J. Gutkowski Jr., E. S. Takle, and F. Otieno, 2001: Evaluation of uncertainties in regional climate change simulations. J. Geophys. Res., 106 (D16), 17 735-17 751.

—, R. W. Arritt, E. S. Takle, W. J. Gutkowski Jr., C. J. Anderson, and M. Segal, 2004: Altered hydrologic feedback in a warming climate introduces a "warming hole." Geophys. Res. Lett., 31, L17109, doi:10.1029/2004GL020528.

Randall, D. A., Harsvardhan, and D. A. Dazlich, 1991: Diurnal variability of the hydrologic cycle in a general circulation model. J. Atmos. Sci., 48, 40-62.

Roads, J. O., S. C. Chen, A. K. Guetter, and K. P. Georgakakos, 1994: Large-scale aspects of the United States hydrologic cycle. Bull. Amer. Meteor. Soc., 75, 1589-1610.

Ruane, A. C., 2010: NARR's atmospheric water cycle components. Part II: Summertime mean and diurnal interactions. J. Hydrometeor., 11, 1220-1233.

Ruiz-Barradas, A., and S. Nigam, 2005: Warm-season rainfall variability over the U.S. Great Plains in observations, NCEP and ERA-40 reanalyses, and NCAR and NASA atmospheric model simulations. J. Climate, 18, 1808-1830.

-, and —, 2006: Great Plains hydroclimate variability: The view from the North American Regional Reanalysis. J. Climate, 19, 3004-3010.
Salathé, E. P., Jr., R. Steed, C. F. Mass, and P. H. Zahn, 2008: A high-resolution climate model for the U.S. Pacific Northwest: Mesoscale feedbacks and local responses to climate change. J. Climate, 21, 5708-5726.

Skamarock, W. C., J. B. Klemp, J. Dudhia, D. O. Gill, D. M. Barker, W. Wang, and J. G. Powers, 2005: A description of the advanced research WRF version 2. NCAR Tech. Note NCAR/TN468+STR, 88 pp. [Available online at http://www.mmm.ucar. edu/wrf/users/docs/arw_v2.pdf.]

Sun, Y., S. Solomon, A. Dai, and R. W. Portmann, 2006: How often does it rain? J. Climate, 19, 916-934.

Takle, E. S., and Coauthors, 1999: Project to Intercompare Regional Climate Simulations (PIRCS): Description and initial results. J. Geophys. Res., 104 (D16), 19 443-19 461.

van der Linden, P., and J. F. B. Mitchell, Eds., 2009: ENSEMBLES: Climate Change and Its Impacts: Summary of research and results from the ENSEMBLES project. Met Office, $160 \mathrm{pp}$. [Available from Met Office, Hadley Center, FitzRoy Road, Exeter EX1 3PB, United Kingdom.]

von Storch, H., and F. W. Zwiers, 1999: Statistical Analysis in Climate Research. Cambridge University Press, 484 pp.

Walko, R. L., and R. Avissar, 2008: The Ocean-Land-Atmosphere Model (OLAM). Part I: Shallow-water tests. Mon. Wea. Rev., 136, 4033-4044.

Zhang, M., W. Lin, C. S. Bretherton, J. J. Hack, and P. J. Rasch, 2003: A modified formulation of fractional stratiform condensation rate in the NCAR Community Atmospheric Model (CAM2). J. Geophys. Res., 108, 4035, doi:10.1029/2002JD002523. 


\section{University Library}

\section{- M M N E R VA A gateway to Melbourne's research publications}

Minerva Access is the Institutional Repository of The University of Melbourne

Author/s:

Bukovsky, Melissa S.;Karoly, David J.

Title:

A regional modeling study of climate change impacts on warm-season precipitation in the Central United States

Date:

2011

Citation:

Bukovsky, M. S., \& Karoly, D. J. (2011). A regional modeling study of climate change impacts on warm-season precipitation in the Central United States. Journal of Climate, 24(7), 1985-2002, doi: 10.1175/2010JCLI3447.1.

Publication Status:

Published

Persistent Link:

http://hdl.handle.net/11343/32782 